\title{
Infância, adolescência e mal-estar na escolarização: o que dizem os especialistas?
}

| ${ }^{1}$ Luciana Gageiro Coutinho, ${ }^{2}$ Cristiana Carneiro |

Resumo: Este artigo é oriundo de uma pesquisa em psicanálise e educação, que aliou estudo de casos múltiplos e pesquisa-intervenção, realizada no Serviço de Psiquiatria da Infância e Adolescência do Instituto de Psiquiatria da UFRJ (SPIA/IPUB-UFRJ). Parte de uma constatação que as condiçóes sociais que sustentam o laço educativo têm sofrido grandes transformaçóes nas últimas décadas. Levando em conta a tese freudiana a respeito do mal-estar inerente à civilização, visa discutir o mal-estar na escolarização de crianças e adolescentes, mais especificamente a partir do discurso dos especialistas que foram convocados a atender os casos estudados. Tece uma reflexão sobre o mal-estar no contexto dos atendimentos clínicos e em seus encaminhamentos, bem como problematiza a hegemonia do discurso médico na compreensão e condução desse processo.

Palavras-chave: infância; adolescência; mal-estar; escolarização; especialistas.

\author{
1 'Faculdade de Educação, \\ Universidade Federal Fluminense. \\ Niterói-RJ, Brasil (lugageiro@uol. \\ com.br). ORCID: 0000-0001- \\ 9887-7895 \\ 2 Fundamentos da Educação, \\ Universidade Federal do Rio de \\ Janeiro. Rio de Janeiro-RJ, Brasil \\ (cristianacarneiro13@gmail.com). \\ ORCID: 0000-0002-4042-1155
}

Recebido em: 18/05/2018 Aprovado em: 09/08/2018 Revisado em: 20/09/2018 


\section{Introdução}

Muito se tem se discutido sobre os entraves no processo de escolarização de crianças e jovens, privilegiando-se ora aspectos individuais de ordem patológica, ora questôes sociais ligadas ao esfacelamento do sistema educacional público. Paralelamente, constatamos uma difusão ilimitada do discurso científico e da cultura medicalizante, que atravessa diversos domínios, da universidade aos centros de saúde e às escolas, adentrando as fronteiras da esfera privada da família e das demais relaçôes pessoais. Seja sob a égide do discurso médico através das categorias diagnósticas contidas no DSM V, seja sob o primado das teorias psicopedagógicas, o cotidiano escolar tem sido constantemente atravessado pelos especialismos, que indicam náo somente maneiras de interpretar aquilo que não vai bem na escolarização, como também apontam para modos de responder técnica e socialmente a isso. De fato, como vimos em estudo exploratório de pesquisa de campo, o índice de encaminhamentos de crianças e adolescentes das escolas para os serviços de saúde mental é alarmante (CARNEIRO; COUTINHO, 2015).

Este artigo é oriundo de uma pesquisa-intervenção sustentada na interface da psicanálise com a educação, realizada no Serviço de Psiquiatria da Infância e Adolescência do Instituto de Psiquiatria da UFRJ (SPIA/IPUB-UFRJ), através de uma parceria envolvendo a Faculdade de Educação da UFF e a Faculdade de Educação da UFRJ. No sentido de ampliar uma leitura sobre o mal-estar na escolarização, o projeto, cuja pesquisa de campo foi feita entre 2013 e 2015, realizou-se por meio de estudo de cinco casos de crianças e adolescentes encaminhados pela escola para o setor. Situamos o mal-estar na escolarização no entrecruzamento dos vários discursos que o constituem, mais especificamente, a família, a escola, os especialistas e a própria criança/adolescente. Dessa forma, o viés mais estrito de pesquisa concentrouse em investigar como o mal-estar na escolarização presente nos cinco casos estudados apareceu no discurso dos diferentes atores que dele participaram e, no seu caráter mais amplo -interventivo e clínico -, buscou mobilizar esses diferentes atores para repensar a situaçáo da criança/adolescente, oferecendo a eles um lugar de endereçamento para suas angústias e questôes. Procurando mapear o modo pelo qual se produz o mal-estar nessas inter-relaçôes a partir dos grandes eixos de análise, tentamos expandir a discussão sobre a problemática dos entraves na escolarização, possibilitando, assim, a reflexão acerca de novas formas de lidar com os impasses; 
afinal, apesar de reconhecermos o mal-estar como inerente à vida na civilização (FREUD, [1930]1996), pensamos que podem ser dados destinos produtivos a ele.

Iremos nos deter aqui, particularmente, na participação dos especialistas convocados a atuar diante das demandas escolares das crianças e adolescentes acompanhados na pesquisa, analisando, através de seus discursos, diferentes modos de intervir diante dessa problemática articulados a diversos olhares sobre a questão.

\section{A produção de diagnósticos e o educar}

Como constatam vários autores interessados na discussão dos modos contemporâneos predominantes no tratamento do mal-estar na cultura, é inegável que a produção de diagnósticos alcançou uma importância cultural imensa, estando presente não somente na prática psiquiátrica stricto sensu, mas em todo campo da assistência à saúde, na educação e nas relações sociais cotidianas mais banais (ZORZANELLI; BEZERRA; COSTA, 2014; DUNKER, 2015; COLLARES; MOISES, 2013). Dessa forma, os desafios relativos ao exercício da parentalidade e da educação escolar hoje são muitas vezes norteados por diagnósticos, medicações e/ou parâmetros presentes nos diversos dispositivos difundidos pelas "autoridades científicas”, que passam a regular e a ressignificar a criança, produzindo um certo anonimato no cerne das relaçóes pais/filhos e professor/aluno. Como observa Lajonquière (1999), deparamo-nos ainda com a menos recente psicologização do cotidiano escolar.

Isso é infelizmente assim, pois o fato de pensar que haveria uma essência psicológica tanto das produçôes morais quanto das epistêmicas, bem como que seria possível usufruir institucionalmente de um saber sobre elas, determina o aparecimento, de direito, de uma série de instâncias de avaliação preventiva, diagnóstico e/ou tratamento escolar ou paraescolar, nas quais hoje em dia cifra-se, paradoxalmente, o destino da empresa pedagógica (LAJONQUIÈRE, 1999, p. 61).

Assim, como sublinha o autor, a escola funciona sob a base de um discurso segundo o qual educar é estimular capacidades psicológicas, o que contribui para individualizar os problemas escolares e fragmentar o olhar para o aluno. E isto está atrelado também a questóes sociais, políticas e econômicas que se entrecruzam na construção de políticas educacionais, seja no âmbito público, seja no âmbito privado do ensino. Supomos que esse fenômeno, já mais antigo e explorado por outros estudos notáveis, como o fez Patto (1999) em A produção do fracasso escolar, parece encontrar 
no contemporâneo novos fundamentos e articulações possíveis a partir do neoorganicismo que se propaga na psiquiatria. Com o avanço das neurociências, aliado aos desenvolvimentos altamente lucrativos da indústria farmacêutica, a compreensão e intervenção nos desajustes presentes na vida escolar de crianças e adolescentes têm sido frequentemente reduzidas a transtornos de ordem orgânica e/ou neuroquímica.

É interessante também observar a evolução dos manuais diagnósticos e suas consequências clínicas e culturais. Como observa Bezerra (2014), a história das teorias e das práticas na psiquiatria está profundamente ligada aos contextos sociais, culturais, epistêmicos, políticos e tecnológicos em que elas se dão. Retomando o pensamento foucaultiano, lembra que toda classificação produz pontos estáveis que organizam nosso olhar sobre a realidade e nossas açôes sobre ela. A partir disso, enfatiza a grande mudança de rumo ocorrida na psiquiatria a partir da publicação do DSM III (Diagnostic and Statistical Manual of Mental Disorders), em 1980. Enquanto em suas primeiras ediçôes o DSM era bastante ancorado nos pressupostos psicanalíticos, trazendo uma visão psicodinâmica dos transtornos, que levava em conta aspectos psicossociais, relacionais e a observação biográfica e longitudinal dos pacientes, a partir da terceira ediçáo, o manual passou a privilegiar o paradigma cognitivo/ comportamental ou biológico dos sintomas, cada vez mais subordinado aos ditames da indústria farmacológica. Assim, desde o DSM III, tais manuais têm adotado critérios cada vez mais descritivos na categorização diagnóstica, que por sua vez se expande progressivamente à medida que esta se reduz a u ma observaçáo superficial e fragmentada de comportamentos e atitudes. Com isso, os diagnósticos deixam de ser pensados como manifestaçôes de conflitos ou desarranjos intrapsíquicos e relacionais para se transformarem apenas em balizas norteadoras da terapia medicamentosa a ser adotada, tendo em vista o paradigma das doenças subjacentes como disfunçóes bioquímicas e entidades anátomo-clínicas. Como observa ainda o autor, tornou-se trivial a ideia de que "a mente é aquilo que o cérebro faz" (BEZERRA, 2014, p. 24). Nesse sentido, com o avanço do paradigma naturalista, ancorado nas novas pesquisas das neurociências, os diagnósticos passam a expressar "um sofrimento sem sujeito" e orientam o olhar dos profissionais que recorrem a eles exclusivamente para uma visão fragmentada da vida, que muitas vezes encontra sustentação fortemente baseada na relação entre a descrição de um comportamento e o uso ou não de um fármaco. Assim, se uma condição clínica melhora com o uso de um antidepressivo, trata-se de uma depressão. 
Caminhando nessa mesma direção, a pesquisa de Dunker (2015) ratifica que a fragmentação do sintoma psíquico em unidades sintomáticas cada vez menores pela psiquiatria contemporânea serve a um projeto social maior que tende a despolitizar o sofrimento, medicalizar o mal-estar e privatizar o sintoma. Nesse sentido, para além da busca por uma maior objetividade de sintomas, traços e sinais visando à construção de categorias mais confiáveis e consensuais, esse autor aponta para a gravidade de questóes éticas e políticas que estão presentes no campo da saúde mental hoje com a construção de uma verdadeira cultura da medicalização generalizada e da naturalização da doença mental.

A verdadeira batalha não é entre psicanalistas e psiquiatras ou entre psicanalistas e cognitivos comportamentais, mas entre os que lidam com o sofimento de sujeitos e os que administram o negócio do mal-estar (DUNKER, 2014, p. 6).

A partir disso, Dunker denuncia um modo perverso de tratar o mal-estar que se dissemina no mundo contemporâneo, já que para ser "um bom negócio" é preciso vender aquilo que promete sua extirpação rápida, numa ilusão de mundo sem mal-estar. De outra forma, poder lidar com o sofrimento pressupóe um acolhimento do mal-estar, justamente para que o mesmo possa ser transformado em vez de descartado. Assim, a proposta de trabalhar com o mal-estar contém em si um elemento de resistência ao fenômeno da medicalização da vida, que avança enormemente e invade cada vez mais o campo da educação. Sobre o resgate do termo mal-estar, Dunker comenta ainda:

É importante distinguir mal-estar, como experiência de mundo, capaz de captar sua incerteza, angústia e indeterminação, ainda que de forma fluida e indeterminada do sofrimento como articulaçáo de demanda em forma de narrativa. Sem isso não conseguimos lidar com certo tipo de insatisfaçáo que não encontra ainda uma nomeação perfeita, que não se codifica nos dispositivos de discurso e de prática encarregados de administrar insatisfações. Daí que o mais simples seja saturar uma nomeação para o mal-estar de forma a inscrevê-lo em uma narrativa (DUNKER, 2014, p. 7).

Dito isso, a propagação e difusão da "cultura psicodiagnóstica" dos DSMs também encontra solo fértil entre os próprios usuários. A emergência do hiperindividualismo, aliado às exigências de performance trazidas pelo imaginário capitalista-liberal, impulsiona a necessidade constante da autogestão e autorreflexão, gerando sofrimentos narcísicos e identitários muitas vezes apaziguados pela oferta de uma nomeação diagnóstica Paralelamente, temos também encontrado diversas argumentaçôes no sentido de que só é possível pensar sobre a alta recorrência desses 
diagnósticos, como é o caso do TDAH nas crianças, através de uma abrangente teoria da cultura contemporânea. Türcke (2016) defende a existência de uma verdadeira cultura do déficit de atenção, diante da fugacidade de estímulos que predomina hoje, gerando uma dificuldade de se ter uma experiência de atenção prolongada, já que vivemos um imperativo de plugar-se e desplugar-se perpétuo. O interessante é que esse autor invoca a importância da escola hoje como um lugar possível de trabalho na contramão desse imperativo da cultura. Chega a fazer propostas efetivas de resgate de ritualizaçooes e exercícios de repetição na escola como possíveis antídotos contra o declínio da experiência da atenção na cultura.

Todos esses fatores talvez possam justificar, em parte, esse enorme fluxo de encaminhamentos da escola à saúde mental (CARNEIRO; COUTINHO, 2015). Nesse sentido, não poderíamos deixar de incluir aqui os atores que atuam junto a esse setor (médicos, psicólogos, psicopedagogos e fonoaudiólogos) e o discurso que produzem sobre a criança, discutindo também os efeitos que isso pode vir a ter sobre ela. Como tem sido a participação desse setor no mal-estar escolar dessas crianças e adolescentes que a ele são encaminhados? Como é o olhar deles sobre esses sujeitos? $\mathrm{O}$ especialista que atende a criança inclui a escola e a família na compreensão do mal-estar na escolarização? E quanto ao seu próprio mal-estar nos atendimentos a essa demanda, o que é feito dele? Essas são algumas questões que procuramos investigar a partir do discurso dos especialistas responsáveis pelo atendimento das crianças e adolescentes participantes da pesquisa.

\section{Procedimentos metodológicos}

A pesquisa teve como objetivo principal investigar o mal-estar na escolarização de crianças e adolescentes por meio da interdisciplinaridade a partir de uma pesquisaintervenção (CASTRO; BESSET, 2008) atrelada ao estudo de casos (YIN, 2005). Em seu projeto-piloto, realizado em 2012, no SPIA/IPUB-UFRJ, a equipe responsável pela pesquisa fez um rastreamento das queixas ligadas à escolarizaçáo dos casos que eram atendidos na triagem do serviço. A partir disso, constatou-se que havia muitas queixas de dificuldade de aprendizagem e agitação. Essas duas queixas foram eleitas como categorias e se tornaram critérios de seleção para os casos que seriam estudados. O grupo elegeu sete casos que atendiam a essas categorias, que foram observados durante os anos de 2013 e 2014, mas somente cinco permaneceram até o final. 
O que a pesquisa se propóe é buscar compreender como se dá o mal-estar, e não somente constatá-lo. O objeto estudado, porém, dentro da perspectiva da pesquisaintervenção, já é modificado pela inserção do pesquisador no campo, havendo uma inter-relação entre os agentes envolvidos. Assim, a relevância da pesquisa-intervenção estaria no fato de ser um operador que permite observar e definir diretamente um objeto e, simultaneamente, agir sobre ele e mudá-lo.

Para tentar responder e entender como o mal-estar era visto / falado, foram construídos eixos de análise, dos quais faziam parte os discursos dos diversos sujeitos presentes em cada caso. Foram quatro eixos formadores da pesquisa: o sujeito (crianças / adolescentes); a família; o especialista; e a escola. Os dados foram coletados durante os anos de 2013 e 2014, a partir de reuniōes mensais com os pais (família); reuniōes com os especialistas (psicólogos, psiquiatras, neurologistas, fonoaudiólogos); reunióes com as próprias crianças / adolescentes; idas à escola das crianças / adolescentes e de seus prontuários. As técnicas utilizadas para a produção do material foram as gravações realizadas de todas as reunióes e, posteriormente, suas transcriçôes; relatórios anuais de cada eixo; e leitura dos prontuários.

$\mathrm{Na}$ análise do material, escolhemos trabalhar aqui com o eixo especialista, e dentro deste, elegemos categorias e subcategorias de acordo com a convergência e a divergência das falas registradas. Em relação aos especialistas, tal investigação foi feita através da leitura das fichas de triagem e dos prontuários das crianças e adolescentes participantes da pesquisa, de entrevistas presenciais ou por telefone com os profissionais, bem como através de reunióes de equipe realizadas no próprio serviço.

A pesquisa em questão teve a autorização do Comitê de Ética (parecer n ${ }^{\circ} 789.946$ ) e da 2a CRE (Coordenadoria Regional de Educação), que nos possibilitou a entrada nas escolas municipais, onde algumas das crianças/adolescentes estavam estudando durante o período de sua participaçáo da pesquisa.

\section{Diagnosticando o mal-estar}

Ao analisar todo o material relativo ao discurso dos especialistas, procuramos primeiramente fazer um levantamento do histórico médico de cada um dos casos através das fichas de triagem e do prontuário. Este muitas vezes era composto de vários documentos relativos a atendimentos anteriores ao SPIA, como laudos, 
receituários, avaliaçóes e encaminhamentos. Desse modo, buscamos observar por quais especialistas as crianças e adolescentes passaram, mesmo antes de chegar ao SPIA, desde que encaminhadas pela primeira vez pela escola. Paralelamente, foi feito um mapeamento dos diagnósticos recebidos pela criança / adolescente ao longo desse percurso, supondo-os como modos de descrever o mal-estar. A partir disso, construímos dois grandes eixos de investigação do discurso dos especialistas, que passaram a nortear a análise de todo material: 1) referências ao sujeito (criança / adolescente) feitas pelo especialista; 2) presença do mal-estar no especialista.

Em relação ao primeiro eixo, pudemos notar no discurso construído pelos profissionais duas formas distintas de se referirem aos sujeitos atendidos. Por um lado, encontramos referências ao mal-estar presente na criança / adolescente predominantemente através da categorização diagnóstica, da descrição da queixa e das manifestaçôes clínicas de forma mais genérica - requisitos assim formulados na ficha de triagem e eventualmente também no prontuário e no discurso falado. Por outro lado, em alguns momentos, encontramos descrições mais livres e singularizadas sobre a criança/ adolescente.

Já no que diz respeito ao segundo eixo, buscamos perceber até que ponto e como o atendimento da criança / adolescente (e de sua família) despertava malestar também no especialista. Partindo do pressuposto freudiano (FREUD [1930] 1996) de que o mal-estar é inerente às relaçôes sociais, era importante para nós saber de que modo aqueles especialistas que lidam com as crianças / adolescentes estão implicados no tratamento do mal-estar. De fato, verificamos que o mal-estar do especialista aparecia de duas maneiras preponderantes: seja em relação à família e a como essa conduzia o tratamento da criança / adolescente; seja em relação ao atendimento propriamente dito, o que foi inferido a partir do número e da frequência de encaminhamentos a outros profissionais.

No que diz respeito às referências ao sujeito criança / adolescente, nas fichas de triagem analisadas, encontramos o mal-estar descrito na queixa (formulada pela escola e pela família) como impulsividade, agitação, baixo rendimento escolar ou - em dois dos cinco casos estudados - já nomeado enquanto categoria diagnóstica: "ele é hiperativo"; "suspeita de TDAH e TOD”. Nesses dois casos, é interessante notar que ambos os adolescentes, um menino e uma menina, já haviam passado por tratamentos anteriores, o menino, por neurologista, psicólogo e psiquiatra (tendo sido diagnosticado com déficit cognitivo e hiperatividade), e a menina, apenas por 
psicólogos (diagnóstico de TDAH e TOD). No caso do menino adolescente, há ainda uma relação de causalidade e determinismo estabelecida entre os dois diagnósticos pelo neurologista que o atendeu quando criança:

V. tem limitação cognitiva evidente definida por QI de 65. Ou seja, funciona intelectualmente em nível subnormal. Portanto, a dificuldade de aprendizagem e o comportamento muitas vezes inadequado, podem ser completamente explicados no caso do adolescente V. (Prontuário, receituário de Serviço de Neurologia).

Este trecho nos remete a uma descrição bastante reducionista do mal-estar escolar, que é atrelado a uma questáo exclusiva ao âmbito cognitivo, como o termo "completamente" sublinha. Além disso, percebemos uma descrição bastante fechada do caso, restrita às categorias médicas, e ao discurso universalizante da ciência, em que um diagnóstico explica o outro. Isso nos faz pensar na "cultura diagnóstica" que vigora nos tempos atuais e que vai além do âmbito da saúde, propagando-se pela escola e pelas diversas relaçóes sociais, de modo que, diante da alta probabilidade de que os adolescentes já tenham sido diagnosticados e medicados durante a infância, tais diagnósticos passam a fazer parte da vida escolar e social deles. Nos outros três casos estudados, as crianças também já haviam passado por tratamentos anteriores, em dois casos, com neurologistas e no outro, apenas com uma psicóloga, mas, diferentemente, a nomeação diagnóstica não aparece na queixa inicial feita no momento de ingresso no SPIA.

Como hipótese diagnóstica, ainda nas fichas de triagem, as três crianças estudadas receberam o TDAH, enquanto nos adolescentes, a menina foi diagnosticada com TDAH e TOD, e o menino com "síndrome genérica" e "dificuldade de aprendizado". A respeito disso, buscamos observar também se tais diagnósticos se mantiveram ou foram modificados ao longo dos atendimentos registrados no prontuário. Nos casos dos dois adolescentes, não houve menção a nenhuma mudança no diagnóstico, apenas encontramos descriçóes mais detalhadas e singularizadas do mal-estar feitas eventualmente por outros profissionais (psiquiatras e psicólogos) que os atenderam posteriormente no SPIA. Já no caso de uma das crianças, o menino G. B., observamos que a hipótese diagnóstica foi questionada pela equipe e a terapia medicamentosa não foi iniciada. Ao tomarmos contato com o caso de G. B., conversamos com o psiquiatra responsável pelo caso e descobrimos que havia controvérsias em sua equipe sobre a necessidade de iniciar a medicação do menino ou não. 
A supervisora reconheceu um comportamento hiperativo dele, mas resolveu não medicá-lo naquele momento por conta da idade, só gosta de medicar com ritalina depois dos 6 [...] O G. é uma criança, que eu até acho, especificamente, de todas as que eu atendi aqui, ele é um que se beneficiaria com a medicação sim, sabe, ele se coloca muito em risco, ele tem muitos comportamentos difícil, ele pula em cima do ventilador, sobe em cima da geladeira, e assim, ele preenche muito os critérios de TDAH, claro que assim, a gente não leva em consideração principalmente em criança, a gente nunca leva só em consideração preencher os critérios, porque os critérios são coisas muito descritivas, e na criança a gente tem todo um contexto, né? Assim, para ser avaliado (Transcrição de entrevista com a psiquiatra responsável pelo caso G. B.).

Enquanto o médico residente que atendia a criança disse "acho que é um caso que precisa de medicação" e "preenche muito os critérios de TDAH” (sic), sua supervisora achou conveniente esperar mais um tempo para tomar uma posição. Assim, mesmo diante da demanda escolar pelo diagnóstico e pelo trata mento psiquiátrico, na reunião da nossa equipe com o residente e a supervisora da psiquiatria, ficou estabelecida que a orientação atual para o atendimento de G. seria o encaminhamento do menino para uma psicoterapia individual, paralelo ao seu acompanhamento familiar e escolar pela nossa equipe. Dessa forma, foi feita uma aposta na possibilidade de que ele não precisasse entrar na medicação já, ou que pelo menos esta não fosse a única forma de tratamento apontada como necessária tanto para a família quanto para a escola. De fato, o adiamento do tratamento medicamentoso foi fundamental nesse caso, pois a partir da intervençáo no contexto escolar e familiar, foi possível verificar uma importante mudança na criança sem a interferência medicamentosa.

A descrição do menino feita pelo médico residente citada acima indica uma abertura no olhar e na descrição do mal-estar da criança em questão, indo além do uso exclusivo das categorias psicodiagnósticas. Este tipo de descrição também se fez presente em outros momentos no atendimento desse menino

Criança bastante agitada e inquieta desde a sala de espera acalma-se um pouco quando peço para fazer um desenho, mesmo assim muito rapidamente). Faço um aviáo de papel e o mesmo sai da sala várias vezes com ele. Ainda pega o lápis e risca a mesa várias vezes mesmo após repreensão da mãe (Prontuário, folha de evolução, psiquiatra responsável pelo caso G. B.).

O comportamento agitado e inquieto se manteve o mesmo na ausência da mãe, nos outros ambientes que frequenta. Uma outra educadora (que fica com ele de 15 em 15 dias) já está reclamando (Prontuário, folha de evolução, psiquiatra responsável pelo caso G. B.).

Nesses trechos, podemos perceber uma preocupação do médico em observar e descrever a criança em interaçáo, discriminando inclusive as possíveis diferenças 
relacionadas a quem está com ela. Isto parece indicar que a criança é vista como um sujeito, cuja compreensão envolve as singularidades observadas também fora do protocolo médico, valorizando a interação com os outros, inclusive com ele próprio. Há ainda outro exemplo deste olhar para o sujeito no caso da adolescente R.

Olha, conta um episódio de um passeio em família em um parque público onde brincou muito com o pai e a mãe seria mais parada. Eu acho que pela menina ter uma coisa de agitação, ela é muito motora, eu não sei se eu classificaria, pelo o que eu tô vendo aqui como TDAH, mas ela é uma criança eminentemente motora. Talvez, uma coisa que a gente vê muito, quanto menos verbal mais motora. Então por ela não falar muito, ela transfere isso pra coisa motora. Ela prefere brincadeiras e jogos muito de corrida, ela prefere atividades físicas muito motoras (Transcriçấo de entrevista com o psiquiatra responsável pelo caso R.).

É outra realidade. Ela tem muitos comportamentos desafiantes, né? Uma coisa bem... bem disruptiva mesmo. Ah! Isso aqui que eu tava tentando lembrar, ela tirou um buquê de rosas né, tinha a ver com rosa... na escola e rasgou na frente de todo mundo. Pelo o que eu tô percebendo aqui na história a dificuldade da R. na escola não parecia ser uma dificuldade no aprendizado né? Já passa por uma certa dificuldade de convivência mesmo (Transcrição de entrevista com o psiquiatra responsável pelo caso R.).

Entretanto, é nítido o contraste desta visão mais contextualizada, na qual se leva em conta a participação da família e da escola no mal-estar, com outros olhares nos quais prevalece uma visão mais universalizante e naturalizante do comportamento.

Enurese noturna; sobrepeso; resquício de tique (funga quando está ansioso ou cansado); compulsão por comida; inquieto na consulta. Fica em pé, apoiando-se nos pés de modo alternado (Prontuário, folha de evolução, psiquiatra responsável pelo caso G. S.).

Está eutímico e fica brincando com seus bonecos (Prontuário, folha de evolução, psiquiatra responsável pelo caso E.).

Observo puerilidade, prosódia e fala (Prontuário, folha de evolução, psiquiatra responsável pelo caso E.).

O que pode ser notado, e deve ser levado em conta na pesquisa, é que a forma narrativa do especialista varia bastante de acordo com o fato de ser falada ou escrita. Nas entrevistas, houve maior detalhamento e tempo para a discussão do caso. A escrita em um prontuário prima por maior concisão e objetividade. No entanto, ainda assim, diante de um mesmo material foi possível encontrar significativas variaçóes nos modos de descrever a criança/ adolescente e o seu mal-estar, algumas mais distanciadas, enquanto em outras podemos notar uma maior implicação do (a) profissional no atendimento. Em um laudo de encaminhamento ao serviço, por exemplo, pudemos observar uma espécie de informação contraditória, o que chamou 
a atenção e nos fez hipotetizar uma possível ambivalência do especialista entre um protocolo mais padronizado e sua própria observação.

G. S. apresenta comportamento autista e foi encaminhado para avaliaçáo psicológica [...] o mesmo tem dificuldades em aceitar o que lhe é proposto. É comunicativo e relata com clareza aquilo que pensa e gosta (Laudo, psicóloga do caso G. S., atendimento anterior ao SPIA).

A atribuição de comportamento autista ao menino feita de forma vaga, sem nenhuma explicação mais detalhada, poderia estar seguindo algum padrão avaliativo da instituiçãa? Estaria esta especialista respondendo a critérios prévios à observação mais singularizada do menino? No mesmo laudo aparece em outro trecho uma menção ao fato de o menino ser "comunicativo", o que é estranhamente associado ao quadro de autismo, já que a comunicação pressupóe uma linguagem solidamente endereçada ao outro. A questão aqui é que a especialista parece não destacar no laudo a própria disparidade como fundamental ao diagnóstico, numa dialogia entre o universal e o particular, incluindo sua própria observação divergente. Isto nos leva a supor que numa cultura medicalizante, muitas vezes, o próprio especialista não se sente autorizado a se incluir como sujeito, também afeito à presença do mal-estar na própria relação com as crianças/ adolescentes e suas famílias. Talvez isso explique porque muitas vezes prevalece a descrição mais comportamental do que relacional nas observaçôes sobre os casos.

\section{Há lugar para o mal-estar no atendimento ao mal-estar?}

$\mathrm{O}$ mal-estar dos especialistas que atendem às diversas demandas de encaminhamento do mal-estar escolar foi por nós identificado sob duas formas principais, que se destacaram no discurso produzido por eles próprios: o mal-estar em relação à família e o mal-estar em relação ao atendimento em si. Foi bastante recorrente na análise do discurso dos especialistas a menção aos entraves trazidos pela família da criança/ adolescente ao atendimento

Mãe chegou 20 minutos atrasada. Mãe não quis marcar em dezembro, oriento a marcar e não passar de janeiro (Prontuário, folha de evolução, psiquiatra responsável pelo caso E).

[...] por uma questão pessoal quem eu vou investir e quem eu não vou, porque quando a gente tem investido em todos a gente se esvaia muito quando náo tem um retorno também [...] Mas eu cheguei, perguntei, não fez nada, tá bom, encerrei a consulta (Transcrição de entrevista com o psiquiatra responsável pelo caso E.).

Eu marquei com ela e ela não veio. Eu acho que não vai combinar com o meu estilo. Porque eles são bem confusos [...] Não trouxe os exames que eu tinha pedido (Transcriçấo de entrevista com o psiquiatra responsável pelo caso G. S.). 
Percebemos nas falas acima que o fato de terem que lidar com as famílias das crianças e adolescentes é fonte recorrente de mal-estar para os especialistas que os atendem. Vimos que algumas vezes a família parece-lhes impeditiva para o tratamento, na medida em que não atende às solicitaçóes feitas por eles relativas a encaminhamentos e à frequência às consultas marcadas. Entretanto, notamos que, enquanto para alguns tal impedimento é definitivo e implica a desistência em atender a criança / adolescente, para outros, ainda que a resistência familiar traga algum mal-estar para a relação, ela é vista como parte integrante do trabalho.

De forma semelhante, procuramos investigar que tipo de menção à escola era feita pelos especialistas, embora sem notarmos um destaque grande para isso no seu discurso. Mesmo assim, julgamos interessante investigar tal aspecto, visando tentar descortinar possíveis nuances relativas ao modo como os especialistas veem a participação do contexto escolar na produção do mal-estar, bem como na condução do seu tratamento.

A professora adorou ritalina (Prontuário, folha de evolução, psiquiatra responsável pelo
caso E.).
Entrevista com mãe: 'Ressaltei que nesse momento os esforços deveriam ser voltados para
melhorar o desempenho de V. na escola para que ele passe de ano e para tentar entrar na
FAETEC conforme diz que deseja [...] Reforcei a importância de manter agora a escolha
do filho (trabalhar + estudar) e que ela deveria conversar com ele sobre a sua alimentaçáo
[...] Sugiro buscar CRE e conversar sobre possibilidade de melhor adequação na escola.
Náo há indicaçáo de psicotrópico no momento (Prontuário, folha de evoluçáo, psicóloga
responsável pelo caso V.).

Os trechos acima revelam uma oscilação bastante frequente na referência à escola por parte dos especialistas. Assim, tal como a família, ora ela é vista apenas como parceira na terapia medicamentosa, ministrando o remédio e fornecendo subsídios ao psiquiatra sobre a dosagem e os horários de prescrição dos remédios, ora a escola é vista como um ambiente propício a novas experiências e enfrentamentos necessários ao mal-estar paralisante.

Já no que se refere ao mal-estar ligado à própria situação do atendimento, um dos seus principais indícios para nós se deu em funçâo do número de encaminhamentos da criança/ adolescente para outros especialistas feitos por aqueles que lhes atendiam no serviço. Algumas vezes, ficava nítido o mal-estar ligado ao impossível do tratamento, como já postulou Freud ([1937] 1980). Consta nos prontuários dos casos acompanhados que, numa mesma consulta com o 
psiquiatra, a adolescente R. foi encaminhada para psicoterapia, natação e terapia de família, enquanto o menino G. S. foi encaminhado pela psiquiatra para a nutricionista, à terapia cognitivo-comportamental e à avaliação fonoaudiológica (2/3/2012; depois de já ter sido encaminhado também à psicopedagoga, a testes para avaliação neuropsicológica e reforço escolar (ambos em 11/5/2012). Já o menino E. foi encaminhado para o Instituto Helena Antipoff (30/5/2013), para a fonoaudióloga (31/7/2013) e para a psicóloga de TCC (28/8/2023). No caso do menino E., consta no prontuário que a família foi cobrada diversas vezes por não cumprir com a agenda de encaminhamentos e, por fim, o caso foi encaminhado para outro setor de psiquiatria, com a justificativa referente ao critério da regionalização nos atendimentos feitos na rede de saúde pública.

Há também algumas outras evidências de um mal-estar presente na relação direta com as crianças/ adolescentes, que, de forma semelhante ao que vimos em relação ao mal-estar ligado à família, pode ser tomado simplesmente como um entrave ou como algo a ser trabalhado na relação terapêutica.

A falta de atenção dele, não sei se ele não me entende ou se não tem interesse ou se é porque é muito menininho mesmo (Prontuário, folha de evolução, psiquiatra responsável pelo caso G. S.).

Durante a entrevista apresentou-se agitado, mudando de assunto quando tentava manter um diálogo com ele ou interrompendo a mãe para falar de assuntos distintos dos que estavam sendo tratados (Prontuário, folha de evolução, psicóloga responsável pelo caso V.).

Já não seria a hora dele mesmo começar a lidar com algumas questôes da vida dele? Ele era tấo despachado para umas coisas e no entanto para outras não era. V. assumia desculpas e não assume, como sempre, uma postura comprometida com suas atitudes, sempre se colocando como o 'perseguido' em todas as coisas (Prontuário, folha de evolução, psicóloga responsável pelo caso V.).

Após explorar as diferentes facetas pelas quais o mal-estar do especialista se faz presente na relação com as crianças e adolescentes que apresentam queixas escolares, somos levados a algumas reflexóes, retomando a discussáo da qual partimos a respeito da cultura medicalizante em que vivemos no mundo contemporâneo. Em que medida o modo de tratar o mal-estar da criança/ adolescente articula-se ao próprio mal-estar daquele que a atende? Será que quanto maior a capacidade de suportar o mal-estar, mais o especialista será capaz de ter um olhar para o sujeito e suportar as singularidades daquilo que escapa ao discurso médico? Nesse sentido, talvez possamos supor que aquele especialista, capaz de suportar o não saber, é também aquele que 
entende que o tratamento envolve outros recursos para além da medicação, incluindo a importância da família e da escola como coadjuvantes no tratamento.

\section{Considerações finais}

Levando-se em conta toda a discussão sobre a medicalização da educação e a redução do mal-estar a categorias diagnósticas naturalizantes e impessoais, faz-se necessário questionar o modo como os conflitos e entraves na vida escolar têm sido concebidos e as consequências que isso gera seja no campo subjetivo daqueles que neles estão envolvidos, seja no campo educativo (familiar e escolar) no que diz respeito ao que sustenta a função do educar. Sabemos que, muitas vezes, a presença de um diagnóstico ou a redução da descrição de um mal-estar escolar à esfera orgânica ou comportamental dificulta a implicação dos próprios sujeitos no seu sofrimento, predominando uma lógica causal externa e/ ou impossível de ser modificada por aquele que sofre. Paralelamente, a redução de problemas escolares a questôes médicas traz problemas para o reconhecimento da autoridade e participaçáo docente no encaminhamento de possíveis mudanças (BOAVENTURA; PAULINO; PEREIRA, 2008).

Como vimos através do material referente ao discurso do especialista, a hegemonia do discurso médico também se reflete na própria relação entre o mesmo e a criança/ adolescente com seu contexto familiar, escolar e social mais amplo, deixando de proporcionar instrumentos para lidar com o campo subjetivo e relacional inerente ao trabalho, o que acaba por se tornar fonte de grande mal-estar.

Com isso, fecha-se um círculo vicioso de difícil transformação, já que talvez possamos supor que, quanto mais insuportável é o mal-estar do especialista, mais o mal-estar da criança/ adolescente é calado e suas possibilidades de elaboração são limitadas. De modo semelhante ao que ocorre na escola, o discurso da eficácia e da generalização que impóe muitas vezes aos professores a injunção de eliminar o impossível de educar gerador de mal-estar, usurpando o lugar do sujeito e sua singularidade, acaba muitas vezes impedindo outros destinos para isso e, assim, o ciclo se perpetua. ${ }^{1}$

\section{Referências}

BEZERRA, B. A psiquiatria contemporânea e seus destinos. In: ZORZANELLI, R.; BEZERRA, B.; COSTA, J. (Orgs.). A criação de diagnósticos na psiquiatria contemporânea. Rio de Janeiro: Garamond, 2014, p. 9-34. 
BOAVENTURA JR., M.; PAULINO, B.; PEREIRA, M. R. O discurso da competência como fator de desautorização docente. In: COLÓQUIO DO LEPSI "Formação de Profissionais e a Criança-Sujeito", 7., 2008, São Paulo. Anais... São Paulo: USP, 2008. Disponível em: <http:// www.proceedings.scielo.br/scielo.php?script=sci_issuetoc $\&$ pid $=00000000320080001 \& 1 n g=p t$ \&nrm=isso>. Acesso em: 15 mar. 2018.

CARNEIRO, C.; COUTINHO, L. G. Infância e adolescência: como chegam as queixas escolares à saúde mental? Educar em Revista, v. 56, p. 181-192, 2015.

CASTRO, L. R.; BESSET, V. Pesquisa-Intervenção na Infância e Juventude. Rio de Janeiro: Nau, 2008.

COLlARES, C. A.; MOISES, M. A. Controle e medicalização da infância. Desidade, n. 1, v. 1, dez. 2013. Disponível em: <http://desidades.ufrj.br/wp-content/uploads/2013/12/DESidades1-port.pdf $>$. Acesso em: 1 mar. 2018.

DUNKER, C. A neurose como encruzilhada narrativa: psicopatologia psicanalítica e diagnóstica psiquiátrica. In: ZORZANELLI, R.; BEZERRA, B.; COSTA, J. (Orgs.). A criação de diagnósticos na psiquiatria contemporânea. Rio de Janeiro: Garamond, 2014, p. 69-106.

. Mal-estar, sofrimento e sintoma. São Paulo: Boitempo, 2015.

FREUD, S. O mal-estar na civilização [1930]. Edição Standard Brasileira das Obras Completas de Sigmund Freud. Rio de Janeiro: Imago, 1996, v. XXI.

. Análise terminável e interminável [1937]. Ediçâo Standard Brasileira das Obras Completas de Sigmund Freud. Rio de Janeiro: Imago, 1980, v. XXIII.

LAJONQUIÈRE, L. Infância e ilusão psicopedagógica. Petrópolis: Vozes, 1999.

PATTO, M. H. S. A produção do fracasso escolar: histórias de submissão e rebeldia. São Paulo: Casa do Psicólogo, 1999.

TÜRCKE, C. Hiperativos! Abaixo a cultura do déficit de atenção. Rio de Janeiro: São Paulo: Paz e Terra, 2016.

YIN, R. K. Estudo de caso: planejamento e métodos tradicionais. 3. ed. Porto Alegre: Bookman, 2005.

ZORZANELLI, R.; BEZERRA, B.; COSTA, J. (Orgs.). A criação de diagnósticos na psiquiatria contemporânea. Rio de Janeiro: Garamond, 2014.

\section{Nota}

${ }^{1}$ L. C. Coutinho e C. Carneiro realizaram a revisão bibliográfica, a descrição metodológica e da pesquisa e redigiram o artigo. 


\section{Abstract}

\section{Childhood, adolescence and malaise in schooling: what do the experts say?}

This article comes from a research in psychoanalysis and education, which allied multiple case study and intervention research, carried out in the Department of Child and Adolescent Psychiatry, Institute of Psychiatry, Rio de Janeiro Federal University (SPIA/ IPUB-UFRJ). It starts with an observation that the social conditions that underpin the educational bond have undergone great transformations in the last decades. Taking Freud's thesis of the malaise inherent in civilization into account, it aims to discuss the malaise in the schooling of children and adolescents, more specifically from the discourse of the specialists who were called to attend the cases studied. It brings a reflection on the malaise in the context of the clinical appointments and in its referrals, and problematizes the hegemony of the medical discourse in the understanding and conduction of this process.

Keywords: childhood; adolescence malaise; schooling; specialists. 